\title{
A FASCINATING INTRODUCTION TO „NONHUMAN PHILOSOPHY“
}

\author{
Daniel C. Marston \\ Marston Psychological Services, Monroeville, PA, USA \\ drdanmarston@comcast.net
}

A Review of the Book

\section{What Would Animals Say If We Asked The Right Questions?}

By Vinciane Despret. 2016.

University of Minnesota Press, Minneapolis, MN. 249 pages.

ISBN 978-0-8166-9239-2 (Paperback Edition, \$30.00, USD)

It is really a pleasure to have the opportunity to describe a book as "an easy-reading book on the philosophy of animal behavior". "Easy-reading" and "philosophy" are not typically words that go together. But that is exactly how I would describe Vinciane Despret's book "What Would Animals Say If We Asked The Right Questions?". It goes beyond summarizing empirical research on animals and delves into the meaning of what we know (or think we know) about animals.

Organized in alphabetical format, chapter headings include "Artists", "Reaction" and "Work". Using these headings helps keep the book interesting and points to main issues readers find within the book's pages. But the real strength to this book lies in the questions (listed as subtitles to the chapter headings) that Despret tries to answer. These questions include "Do animals have a sense of prestige?", "Might the dominance of males be a myth?" and "Why do we say that cows don't do anything?". To give you a sense of how far-reaching the book extends, take note that two of the chapter questions are "Do goats agree with statistics?" and "Do chimpanzees die like we do?".

There is not a great deal of research summarized in this book. Its focus is primarily on philosophical conclusions related to what we know about animal behaviors. One or a few empirical studies are included in most chapters and they serve mainly to set the 
stage. These empirical results are then incorporated with philosophical works, general publications, books and Despret's experiences and analyses to address what meaning we can take away from scientific findings. Some of the more fascinating material centers on Despret's personal conversations with scientists and philosophers about the book's topics (in order to read those, be sure not to skip the book's footnotes).

Describing this book as "easy-reading" does not mean that the material is "easy". There is considerable depth and complexity to all the topics addressed. But Despret does an amazing job at keeping each topic's complexity contained within ten pages or less. There is very little space wasted in any of the chapters as each page covers important material for more fully understanding challenging issues.

Students and professionals are likely to find a lot to appreciate about Despret's book. It really is a resource for anyone who wants to delve deeply into understanding animals and what animal research tells about the world. It is a philosophical text so the conclusions are ones that are open to different interpretations. Despret presents strong evidence for all the book's conclusions but draw different conclusions from the same material. Having a book that provides answers to important questions while also providing sufficient room for some readers to come up with different answers is one thing that makes this text so worthwhile.

Several years ago, I was working on a book exploring the intersection of clinical and comparative psychology. My co-author and I were looking at different ways to address issues that had not been addressed in any previous work. When exploring how humanistic psychologists (clinicians that emphasize the importance of "meaning" and "purpose" in human functioning) could incorporate comparative psychology work, one relevant question that arose was "Do animals live meaningful lives?". Although Despret does not address this topic directly, this type of higher-level of question is emphasized throughout this book. I would also say that the issue of "meaning" and "purpose" for animals (along with how we define these terms) is relevant throughout many of the book's topics. It is a book that I really wish had been available when I was writing my book, as I think its approach to questions few other authors tackle would have added considerably to the material we addressed.

This book is so unique in style and topic that I find it difficult to compare it to any other text. For me, it is a type of book I rarely encounter anymore where the author triggers my interest in topics I had not much considered. Despite my familiarity with animal behavior research (particularly research included in scientific journals like Journal of the Experimental Analysis of Behavior, Journal of Applied Behavior Analysis and Journal of Comparative Psychology), I was not aware that there was a whole field of academic publishing that could best be called "Nonhuman Philosophy". This book serves as an excellent introduction to the field and certainly stimulates interest in reading more.

When considering how this book helps better understand human psychology, it is useful to note the role of "comparative psychology" when it comes to this issue. This field is dedicated to understanding psychological constructs across species. In this way, behaviors can be more fully understood separate from factors unique to individual species exhibiting the behaviors. When the famous psychologist B.F. Skinner studied behaviors in nonhuman animals, but then applied his findings to his theory of human behavior (Skinner, 1953), he was emphasizing the comparative approach to understanding what the term "behaviors" mean. Despret takes a similar cross-species 
approach to defining terms like "compromise", "art" and "language" (in chapters titled "Can Animals Compromise?", "Do Birds Make Art?" and "Who Invented Language and Mathematics?"). Taking this approach helps any reader considering human psychology to take a deeper look at what important terms and constructs might mean.

If there is one limitation to this book it is that is can be difficult to follow at times. I expect there are two reasons for this. One is that it is a translation of a book originally written in French. Some of the sections do not seem to translate easily into English. And then a second reason is that Despret does not always approach this as an introductory text. Some analyses and explanations seem to assume a familiarity with authors and concepts not likely to be familiar to those outside the philosophy fields. I found myself saying several times “This author sounds fascinating, I wonder who it is?". Providing some explanations might have helped make this book even stronger but, as it is, readers can do just as well by having their favorite search engine or online encyclopedia readily available.

Despret's work here is a useful reference for anyone who wants to go further beyond understanding empirically what we know about animal behavior. It provides a practical but still detailed guide for ideas about what research findings mean for understanding animals. In this way, I think it offers a resource to help address difficulties faced by comparative psychology and other fields dedicated to studying animal behavior. Abramson (2015a) summarized these difficulties in an article entitled "A crisis in comparative psychology: Where have all the undergraduates gone?" and these difficulties were explored further in subsequent commentaries (including Abramson, 2015b; Beilert \& Gallup, 2015 and Vasconcelos \& Pandeirada, 2015). Undergraduate students show interest in understanding animals but often lack access to courses and motivation to seek out opportunities for understanding animal research. When only presented in its "dry" empirical format, comparative psychology research does not foster motivation for students seeking this material out, in part because its relationship to understanding issues students find important is unclear. Books like the one described here can go a long way towards melding together students' interests in better understanding the natural world and motivation for reading and appreciating animal behavior research.

\section{ABOUT THE AUTHOR}

Daniel Marston, $\mathrm{PhD}, \mathrm{ABPP}$ is a licensed behavioral psychologist who specializes in the treatment of neurobehavioral disorders. He is the primary author of the book "Comparative Psychology for Clinical Psychologists and Therapists: What Studying Animal Behavior Tells Us About Human Psychology" and the author of Autism \& Independence. 


\section{REFERENCES}

Abramson, C. I. (2015a). A crisis in comparative psychology: where have all the undergraduates gone?. Frontiers in psychology, 6, 1500.

Abramson, C. I. (2015b). A crisis in comparative psychology: Where have all the undergraduates gone? Additional comments. Comprehensive Psychology, 4, 10-IT.

Bielert, C. F., \& Gallup, A. C. (2015). A clarion call or a swan song? Commentary: A crisis in comparative psychology: where have all the undergraduates gone?. Frontiers in psychology, 6, 1867.

Skinner, B. F. (1953). Science and human behavior. Simon and Schuster.

Vasconcelos, M., \& Pandeirada, J. N. (2015). Forgetting the Past and Neglecting the Future.

Commentary: A Crisis in Comparative Psychology: Where Have All the Undergraduates

Gone?. Frontiers in psychology, 6, 1823. 